\title{
Comparison of efficacy of the intermittent pneumatic compression with a high- and low- pressure application in reducing the lower limbs phlebolymphedema
}

\author{
This article was published in the following Dove Press journal: \\ Therapeutics and Clinical Risk Management \\ 7 October 2015 \\ Number of times this article has been viewed
}

\section{Jakub Taradaj' \\ Joanna Rosińczuk ${ }^{2}$ \\ Robert Dymarek ${ }^{2}$ \\ Tomasz Halski ${ }^{3}$ \\ Winfried Schneider ${ }^{4}$}

'Department of Physiotherapy Basics, Academy School of Physical Education in Katowice, Katowice, ${ }^{2}$ Department of Nervous System Diseases, University of Medicine in Wroclaw, Wroclaw, ${ }^{3}$ Institute of Physiotherapy, Public Higher Medical Professional School in Opole, Opole, Poland; ${ }^{4}$ Lymphology Center in Bad Berleburg, Bad Berleburg, Germany
Correspondence: Robert Dymarek Department of Nervous System Diseases, University of Medicine in Wroclaw, Bartla 5 Street, 5I-618 Wroclaw, Poland

$\mathrm{Tel}+48$ 7I 784 I8I3

Fax +48 7I 3459324

Email r.dymarek@gmail.com
Introduction: The primary lymphedema and chronic venous insufficiency present an important medical problem, and effective physical therapeutic methods to treat this problem are still at the search phase. The aim of this study was to compare the efficacy of intermittent pneumatic compression (IPC) of a high- or low-pressure level in the treatment of primary phlebolymphedema of the lower limbs.

Methods: The study included 81 patients with chronic venous insufficiency and primary lymphedema of the lower limbs. Group A consisted of 28 patients who underwent a monthly antiedematous therapy including a manual lymphatic drainage, multilayer bandaging, and IPC with the output pressure of $120 \mathrm{mmHg}$. Group B consisted of 27 patients who underwent the same basic treatment as group A and IPC with the output pressure of $60 \mathrm{mmHg}$. Group C (control) consisted of 26 patients who underwent only a basic treatment - without IPC.

Results: After completion of the study, it was found that the greatest reduction of edema occurred in patients who underwent treatment with a pressure of $120 \mathrm{mmHg}$. The comparison of percentage reduction of edema showed a statistically significant advantage of the group A over groups $\mathrm{B}$ and $\mathrm{C}$, both for the changes in the right $(P=0.01)$ and the left limb $(P=0.01)$. Results in patients undergoing intermittent compression of the lower pressure $(60 \mathrm{mmHg})$ were similar to those obtained in the control group.

Conclusion: The IPC with the pressure of $120 \mathrm{mmHg}$ inside the chambers effectively helps to reduce a phlebolymphedema. Furthermore, it appears that the treatments with a pressure of $60 \mathrm{mmHg}$ are ineffective and their application becomes useless only in the antiedematous therapy.

Keywords: perometric measurement, intermittent pneumatic compression (IPC), phlebolymphedema, chamber pressure

\section{Introduction}

Lymphedema of the lower limbs, which occurs in patients with chronic venous insufficiency, is the result of disorders in tissue fluid, lymph, and venous blood circulation in a limb area, leading to a noticeable disparity in its appearance, reduced joint mobility, and frequent inflammation of the skin, blood vessels, and lymph nodes. ${ }^{1-3}$

Currently, it is believed that the number of documented cases of lymphedema of the lower limbs could account for approximately 6 million people worldwide (4.6 million in the age group 40-60), in which $60 \%$ of patients suffer from chronic venous insufficiency. ${ }^{4}$ The only data collected in Poland, involving the most extensively studied population so far (40,096 patients contacting a General Practitioner [GP]), were 
obtained in a multicenter cross-sectional study, whose results were published in 2003. ${ }^{5}$ The incidence of phlebolymphedema in patients diagnosed with chronic venous insufficiency in Poland was estimated to be $10 \%$. Studies conducted in Western Europe show that the most common are telangiectasia and reticular veins as they occur in approximately $65 \%$ of women and $>50 \%$ of men. In contrast, lower limbs varices affect $10 \%-20 \%$ of men and $25 \%-33 \%$ of women. ${ }^{3,6-8}$

The results of epidemiological studies and papers referring to the financial costs of treating patients with phlebolymphedema clearly indicate the great need to seek minimally invasive, safe, and effective, but above all, low-cost therapeutic methods, and because of its chronic nature, also giving the opportunity to the patient to apply them at home.

Compression therapy is a method that exerts pressure on the limb from the outside, which increases the drainage from the veins and lymph, and this prevents the accumulation of fluid in the extravascular space. ${ }^{9}$ Compression therapy includes pneumatic massage device, multilayer limb bandaging, and compression garments with varying pressure. Intermittent pneumatic compression (IPC) is the physical method often used in sports and medicine, as evidenced by numerous bibliographic data from PubMed, Medline, and Physiotherapy Evidence Database (PEDro). ${ }^{10-14}$

Despite a few clinical trials in lymphedema, a mutual consensus on the treatment parameters was not established. Some authors recommend the use of pressure from $40 \mathrm{mmHg}$ to $60 \mathrm{mmHg},{ }^{15-17}$ while others recommend significantly higher values from $80 \mathrm{mmHg}$ to $130 \mathrm{mmHg} .{ }^{18-20}$

The aim of this study was to compare the efficacy of IPC with a high- or low-pressure level in the treatment of primary phlebolymphedema of the lower limbs in patients with chronic venous insufficiency. It was evaluated whether the different level of output pressure in chambers during IPC procedures is a factor significantly influencing the effectiveness of antiedematous treatment in patients with chronic venous insufficiency and whether a high- or low-pressure value is more effective in edema reduction.

\section{Materials and methods \\ Study design}

This research project was approved by the Bioethics Committee of the Academy School of Physical Education in Katowice (number 5/2013, May 16, 2013). The research was conducted at the Limf-Med Hospital in Chorzow, in the period from July 1, 2013 to July 4, 2014.

The study included the patients with chronic venous insufficiency with unilateral or bilateral primary lymphedema of the lower limbs (lasting at least 3 months). Eligibility and clinical evaluation of patients were performed by a team consisting of a vascular surgeon and an angiologist, an internist, an oncologist, and a physiotherapist.

Patients were assigned to one of the three comparison groups, A, B, and C. The basis for inclusion of patients was a vascular Doppler examination with the use of the Doppler Duplex Hitachi EUB 5500 device. The study included an assessment of venous reflux in superficial and deep system and in the area of perforators. According to the standards, the venous reflux is present with a valve insufficiency of $>0.5$ seconds at the compression trial. ${ }^{21,22}$ The patients were also subjected to specification according to the Clinical Etiology Anatomy Pathophysiology (CEAP) classification of chronic venous insufficiency. ${ }^{22-24}$ The inclusion criteria also included positive Stemmer's sign (Figure 1) and 20-second compression attempt of the skin (Figure 2 ). The severity of phlebolymphedema was evaluated based on two clinical classifications for lower limbs by Olszewski and Brunner. ${ }^{18,25,26}$ In the case of women to be eligible for treatment, each treatment was adjusted to the beginning of the follicular phase of the menstrual cycle and initiated only after menstruation. Exclusion criteria included patients with active thromboembolic disease, diabetes, peripheral arterial disease (ankle-brachial index $<0.8$ ), rheumatoid arthritis, parasitosis, generalized scleroderma, collagenoses, dermatitis, psoriasis, and advanced coronary artery disease (III and IV $^{0}$ in New York Heart Association [NYHA] classification) - edema of cardiogenic origin, patients with polyneuropathy of the lower limbs, as well as patients with pacemakers and patients taking steroid and/or diuretic medications. The study also excluded patients with edema of renal or hepatic nature and patients with postoperative

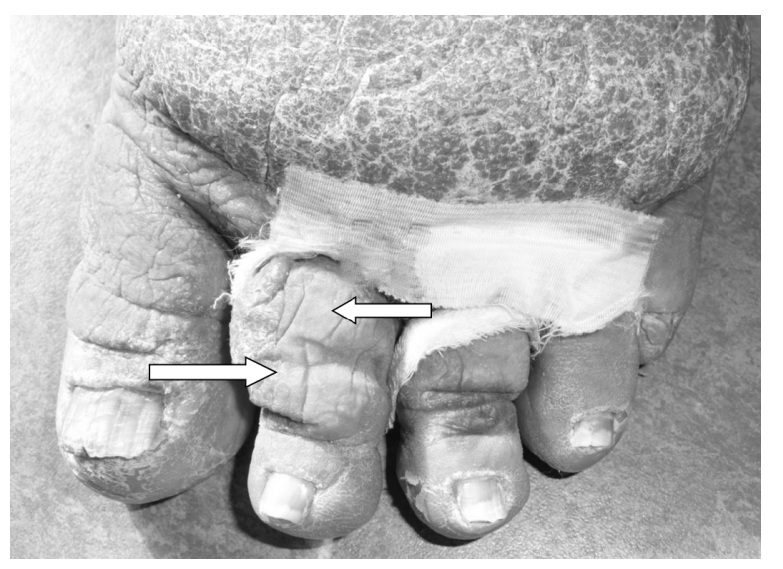

Figure I Characteristic changes (infiltration of lymph) within the second toe - a massive Stemmer's sign. 


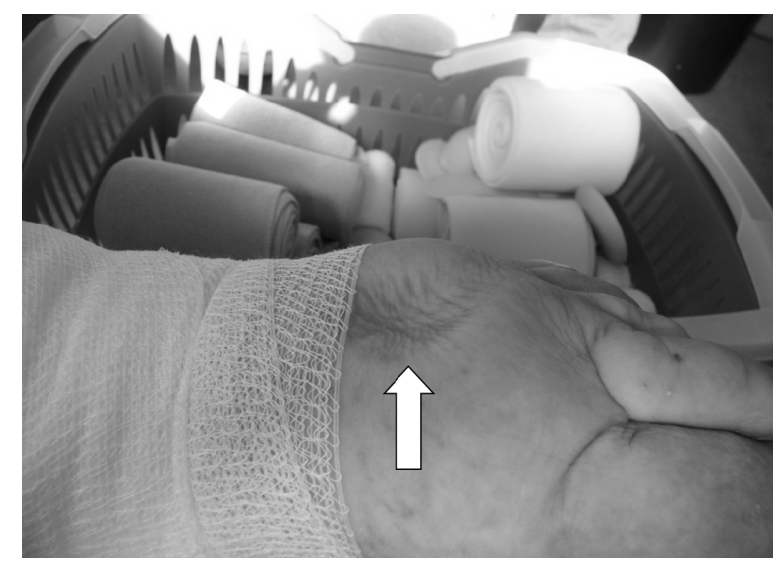

Figure 2 Positive compression test - a specific indentation characteristic for protein-rich fluid under the skin.

lymphedema (secondary) and cancer. Patients with irregular menstrual cycles (6-month observation before entering the study) in premenopausal period were also excluded.

\section{Characteristics of the study population}

Prior to the study, participants were briefed on the objective of the study and given the opportunity to refuse further participation at any point. All participants gave their informed consent to be included in the study (statement confirmation) and consent was also given by the patient for the use of the photo in Figure 6. The study was conducted in accordance with the principle of intention to treat (patients excluded from the research at subsequent stages for various reasons were still provided with a basic lymphatic care).

The group of 81 patients eligible for the treatment was assigned to three comparative groups. A random selection for particular groups was carried out continuously throughout the duration of the study, that is, each new patient was subjected to randomization by computer random number generator using a Monte Carlo method, and based on the result of the draw, the patient was assigned to a given control group according to the CONSORT guidelines (Figure 3).

The characteristics of the study population within each group are presented in Tables 1-4. The groups were homogeneous taking into account all the factors characteristic for the patients, as well as the initial size and the clinical stage of chronic venous and lymphatic edema of the lower limbs.

\section{Treatment procedures}

All patients were treated on an outpatient basis in a lymphatic clinic, where they received a 4-week comprehensive antiedema therapy (manual lymphatic drainage and multilayer bandaging) and pharmacotherapy (phlebotropic drug - Diosmin $500 \mathrm{mg}$ two tablets administered per day).

The manual lymphatic drainage was performed by the physical therapist starting from the proximal preparation (ie, gentle strokes on the so-called venous angles - skin area over the subclavian veins), then the skin layers over the cisterna chyli (a saccular area of dilatation in the lymphatic channels as the beginning of the thoracic lymph duct) connected with the diaphragm breathing exercises, and finally segmental massage of the entire upper limb. The massage was finished with a proximal preparation technique. Lymphatic massage took 50 minutes and was performed once a day, three times a week (Monday, Wednesday, and Friday).

After performing the manual lymphatic drainage (before placing a limb low or resting), the compression therapy was applied - multilayer bandaging with an external pressure of 40-50 mmHg. The first layer was an orthopedic sleeve Tubula (Matopat Bella-Handelv LLC, Torun, Kujavy, Poland) applied directly onto the surface of the limb. Then the elastic Matolast support bandage (Matopat Bella-Handelv LLC) was used for accurate and precise overlay on the toes. The next layer was a RoltaSoft cotton (Paul Hartmann LLC, Pabianice, Lodzkie, Poland), which starts from the distal part and was gradually applied to the entire limb. The outer layer consisted of evenly placed short-stretch bandage (Paul Hartmann LLC), which was applied for 24 hours. In cases of bilateral edema, bandaging was performed on both limbs in accordance with the standards to the level of the knee joint and not to the height of the groin as in the case of bandaging a single limb with phlebolymphedema. ${ }^{5,27}$

In addition, the IPC treatment was performed in group $\mathrm{A}$ and $\mathrm{B}$ patients before manual lymphatic drainage treatments with the use of the 12-chamber apparatus Lymphatron DL1200 (Technomex LLC, Gliwice, Upper Silesia, Poland; Figures 4 and 5). In group A, the external pressure used was as high as $120 \mathrm{mmHg}$, and in group B, it was $60 \mathrm{mmHg}$. A single treatment took 45 minutes. The procedure consisted in sequentially filling the chambers of the sleeve starting from the circumference going to closer sections of a limb. A singlechamber filling time was 3 seconds (when the air was pumped to the next chamber, the previous ones did not deflate, which means that they maintained full pressure). In cases of unilateral edema, a single compression sleeve was used, and in patients with bilateral edema, a double sleeve was used. The treatment was conducted once a day, three times a week (Monday, Wednesday, and Friday). Manual lymphatic drainage treatments and multilayer bandaging were performed in all patients from groups A, B, and C by the same therapist. 


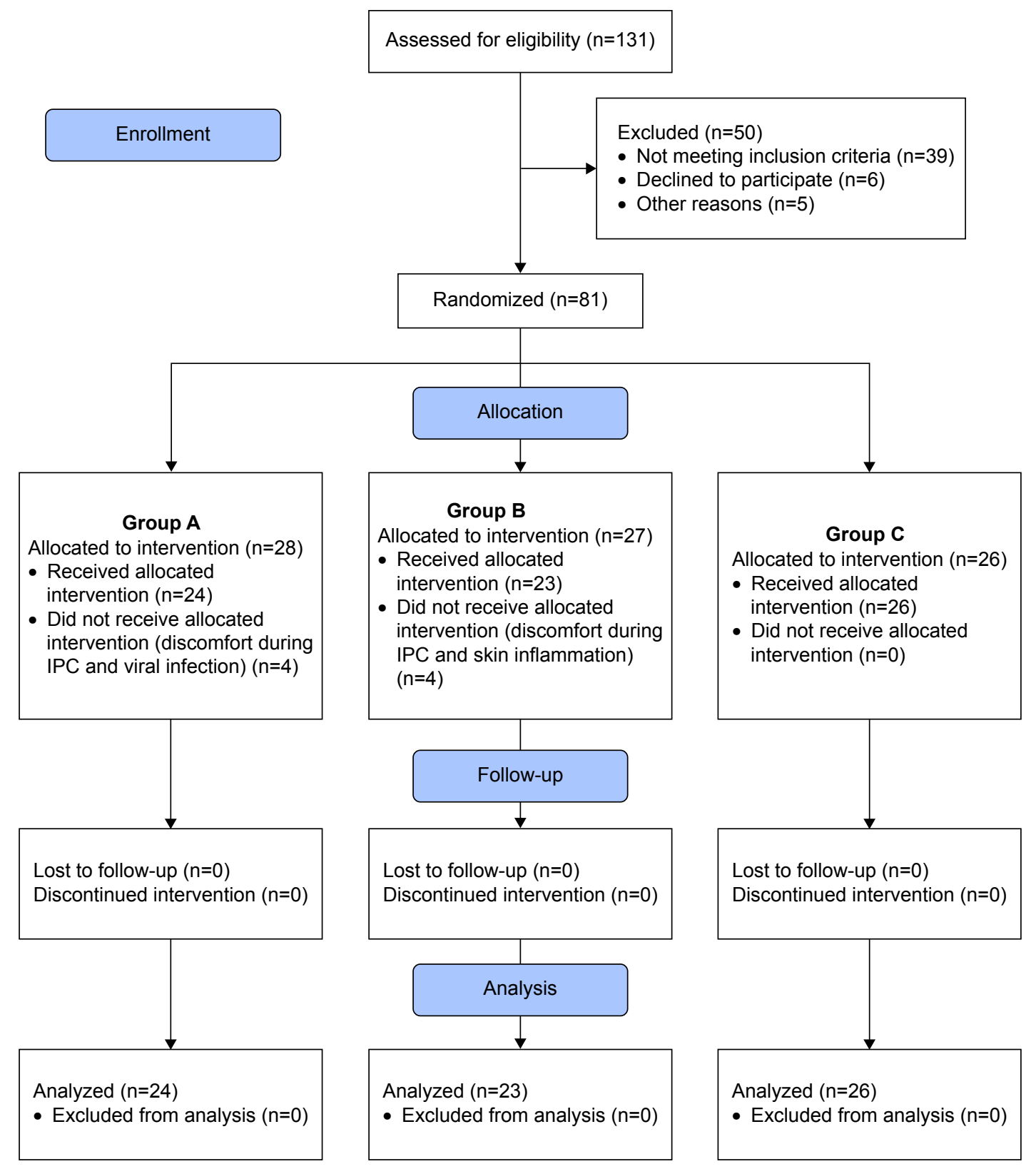

Figure 3 Study flowchart and CONSORT diagram.

Abbreviation: IPC, intermittent pneumatic compression.

\section{Methods and measuring error}

Lower limb volume measurements were performed by the same technician in all three groups of patients before and after a monthly therapy.

To assess the volume of a limb, an optoelectronic Perometer 400 T was used (Pero-System Messgeräte GmbH, Wuppertal, North Rhine-Westphalia, Germany; Figure 6), which was connected to a personal computer. This method allowed to estimate the volume of a limb with a measuring error of $0.5 \%$ (manufacturer's data). The assessment technique was based on a special ring, equipped with a system of 378 Lighting Emitting Diode (LED) diodes emitting the infrared radiation. Within the ring, there were also the optical sensors that receive electromagnetic stimuli. During the course of measurement, the limb was located inside the ring on the diode-sensor lines. The registered light pulses on the detectors were turned into electronic signals. The ring was moved during measurement to cover the entire limb. Computer software allowed for the analysis of volume and circumference at any stage of measurement.

For the purpose of this research, we made our own estimates of measurement error of Perometer 400T. On the basis of ten patients who were randomly selected for the study, each of them was subjected to 20 consecutive measurements of lower limb with edema (a total of 200 measurements). 
Table I General characteristics of the study population in groups $A, B$, and $C$

\begin{tabular}{|c|c|c|c|c|}
\hline & Group A & Group B & Group C & $P$-value \\
\hline Number of patients & 24 & 23 & 26 & $>0.05$ \\
\hline Sex & $15 \mathrm{~F} / 9 \mathrm{M}$ & $13 \mathrm{~F} / \mathrm{IOM}$ & $16 \mathrm{~F} / 10 \mathrm{M}$ & $>0.05$ \\
\hline Number of smokers & 13 & 12 & 13 & $>0.05$ \\
\hline \multicolumn{5}{|l|}{ Age (years) } \\
\hline Average & 49.5 & 51.5 & 52.2 & \multirow[t]{3}{*}{$>0.05$} \\
\hline Min-max & $42.3-62.2$ & $44.6-60.3$ & $45.6-63.4$ & \\
\hline SD & 4.2 & 6.1 & 7.1 & \\
\hline \multicolumn{5}{|l|}{ BMI $\left(\mathrm{kg} / \mathrm{m}^{2}\right)$} \\
\hline Average & 26.4 & 27.7 & 27.8 & \multirow[t]{3}{*}{$>0.05$} \\
\hline Min-max & $22.3-32.5$ & $19.6-32.2$ & $20.2-32.4$ & \\
\hline SD & 3.7 & 4.2 & 4.6 & \\
\hline \multicolumn{5}{|c|}{ Edema occurrence (years) } \\
\hline Average & 5.6 & 5.6 & 5.8 & \multirow[t]{3}{*}{$>0.05$} \\
\hline Min-max & $0.8-10.4$ & $0.6-12.6$ & $0.6-14.2$ & \\
\hline SD & 4.2 & 4.4 & 4.8 & \\
\hline \multicolumn{5}{|c|}{ Initial volume of edema $\left(\mathrm{cm}^{3}\right)$} \\
\hline Average & & & & \multirow[t]{3}{*}{$>0.05$} \\
\hline $\mathrm{R}$ & |4,423.34 & $14,562.02$ & $\mid 4,078.22$ & \\
\hline L & $|3,902.1|$ & $14,103.23$ & $|3,944.2|$ & \\
\hline \multicolumn{5}{|l|}{$S D$} \\
\hline $\mathrm{R}$ & $4,781.12$ & $4,454.24$ & $4,303.88$ & \\
\hline L & $4,423.33$ & $4,223.25$ & $3,993.84$ & \\
\hline
\end{tabular}

Notes: Group A underwent a monthly antiedematous therapy including a manual lymphatic drainage, multilayer bandaging, and IPC with the output pressure of $120 \mathrm{mmHg}$. Group B underwent the same basic treatment as group A and IPC with the output pressure of $60 \mathrm{mmHg}$. Group C (control) underwent only a basic treatment without IPC.

Abbreviations: BMI, body mass index; F, female; L, left limb; max, maximum; M, male; min, minimum; R, right limb; SD, standard deviation; IPC, intermittent pneumatic compression.

The absolute error $(\Delta X)$ of the measurement of the total lower limb volume was calculated using the formula:

$$
\Delta X=X-X_{0},
$$

where $X$ is the value measured in the next trial and $X_{0}$ is the correct value (mean) calculated after 20 trials.

Then, the relative error was estimated $\left(\delta_{X}\right)$ from the formula:

$$
\delta_{X}=\frac{\Delta X}{X_{0}}
$$

where $\Delta X$ is the absolute error and $X$ is the value measured at a given trial.
Table 2 Characteristics of chronic venous insufficiency in given groups

\begin{tabular}{lllll}
\hline $\begin{array}{l}\text { CEAP scale } \\
\text { (number of patients) }\end{array}$ & Group A & Group B & Group C & P-value \\
\hline $\mathrm{C}_{3} \mathrm{E}_{\mathrm{P}} \mathrm{A}_{\mathrm{S} 2,3} \mathrm{P}_{\mathrm{R}}$ & $\mathrm{IOR} / \mathrm{IOL}$ & $9 \mathrm{R} / \mathrm{IIL}$ & $10 \mathrm{R} / \mathrm{IIL}$ & $>0.05$ \\
$\mathrm{C}_{4} \mathrm{E}_{\mathrm{P}} \mathrm{A}_{\mathrm{S} 2 \mathrm{D} 13} \mathrm{P}_{\mathrm{R}}$ & $8 \mathrm{R} / 7 \mathrm{~L}$ & $8 \mathrm{R} / 7 \mathrm{~L}$ & $9 \mathrm{R} / 8 \mathrm{~L}$ & $>0.05$ \\
$\mathrm{C}_{4} \mathrm{E}_{\mathrm{P}} \mathrm{A}_{\mathrm{S} 2,3 \mathrm{D} 13,14 \mathrm{P} 18 \mathrm{P}_{\mathrm{R}}}$ & $6 \mathrm{R} / 7 \mathrm{~L}$ & $6 \mathrm{R} / 5 \mathrm{~L}$ & $7 \mathrm{R} / 7 \mathrm{~L}$ & $>0.05$ \\
\hline
\end{tabular}

Notes: ${ }^{2} C_{3} E_{P} A_{52,3} P_{R}$, primary failure, edema, the presence of reflux above and below the knee in saphenous vein; $C_{4} E_{P} A_{52 D 13} P_{R}$, primary failure, edema and trophic changes in the skin and subcutaneous tissue, the presence of reflux above and below the knee in saphenous vein and femoral vein; and $\mathrm{C}_{4} \mathrm{E}_{\mathrm{P}} \mathrm{A}_{52,3 \mathrm{D} 13,14 \mathrm{P} 18} \mathrm{P}_{\mathrm{R}}$, primary failure, edema and trophic changes in the skin and subcutaneous tissue, the presence of reflux above and below the knee in saphenous, femoral, and popliteal vein and shank perforators. Group A underwent a monthly antiedematous therapy including a manual lymphatic drainage, multilayer bandaging, and IPC with the output pressure of $120 \mathrm{mmHg}$. Group B underwent the same basic treatment as group A and IPC with the output pressure of $60 \mathrm{mmHg}$. Group C (control) underwent only a basic treatment - without IPC.

Abbreviations: R, right limb; L, left limb; IPC, intermittent pneumatic compression; CEAP, clinical etiology anatomy pathophysiology.

Then, the mean percentage error (relative error expressed in percentage) of all 20 measurements for each limb was calculated. ${ }^{28}$

The final measurement error by the authors' calculations (based on the error results of ten lower limbs) was higher than that specified by the manufacturer (average $=1.26 \%$, and standard deviation $[\mathrm{SD}]=1.03 \%)$. The results of the measurement error were obtained for three right and seven left lower limbs (mean limb volume amounted to $15,532.44 \mathrm{~cm}^{3}$, and $\left.5.092 .31 \mathrm{~cm}^{3} \mathrm{SD}\right)$.

The tests with perometer measured the changes of real values (absolute) in the total volume of the limb and its sections - the volume of the foot, shank, and thigh - and additionally percentage changes for edema reduction were calculated using the following formula:

$$
\mathrm{d} P \%=\frac{\left(P_{1}-P_{n}\right) \times 100 \%}{P_{1}},
$$

where $\mathrm{d} P \%$ is the percentage change in a given parameter, $P_{1}$ the initial real value of a given parameter (measured before treatment), and $P_{n}$ the final real value of a given parameter (measured after treatment). ${ }^{28}$

Table 3 Patients' characteristics in terms of edema according to categories by Olszewski

\begin{tabular}{lllll}
\hline $\begin{array}{l}\text { Edema severity according to Olszewski's } \\
\text { (number of patients) }\end{array}$ & Group A & Group B & Group C & P-value \\
\hline Ila & $5 R / 3 \mathrm{~L}$ & $4 \mathrm{R} / 4 \mathrm{~L}$ & $4 \mathrm{R} / 3 \mathrm{~L}$ & $>0.05$ \\
$\mathrm{IVa}$ & $1 \mathrm{R} / 9 \mathrm{~L}$ & $10 \mathrm{R} / 8 \mathrm{~L}$ & $12 \mathrm{R} / 10 \mathrm{~L}$ & $>0.05$ \\
$\mathrm{IVc}$ & $2 \mathrm{R} / \mathrm{IL}$ & $2 \mathrm{R} / \mathrm{IP}$ & $3 \mathrm{R} / 2 \mathrm{~L}$ & $>0.05$ \\
\hline
\end{tabular}

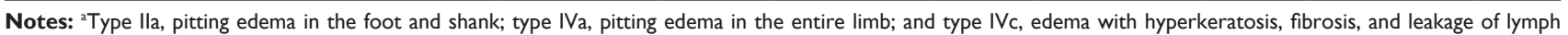
in the entire limb. Group A underwent a monthly antiedematous therapy including a manual lymphatic drainage, multilayer bandaging, and IPC with the output pressure of $120 \mathrm{mmHg}$. Group B underwent the same basic treatment as group A and IPC with the output pressure of $60 \mathrm{mmHg}$. Group C (control) underwent only a basic treatment without IPC.

Abbreviations: R, right limb; L, left limb; IPC, intermittent pneumatic compression. 
Table 4 Patients' characteristics in terms of edema according to categories by Brunner

\begin{tabular}{|c|c|c|c|c|}
\hline $\begin{array}{l}\text { Edema severity according to } \\
\text { Brunner }^{\text {a }} \text { (number of patients) }\end{array}$ & Group A & Group B & Group C & $P$-value \\
\hline II & $2 \mathrm{R} / \mathrm{IL}$ & $2 R / I L$ & $3 R / 2 L$ & $>0.05$ \\
\hline III & 9R/7L & $8 R / 7 L$ & $9 \mathrm{R} / 6 \mathrm{~L}$ & $>0.05$ \\
\hline IV & $2 \mathrm{R} / \mathrm{IL}$ & $2 \mathrm{R} / \mathrm{IL}$ & $3 R / 2 L$ & $>0.05$ \\
\hline V & $I R / I L$ & $I R / I L$ & IR/IL & $>0.05$ \\
\hline
\end{tabular}

Notes: aGrade II, all-day edema resolves spontaneously after the night, with positive Stemmer's sign; grade III, constant edema does not pit and does not significantly reduce upon limb elevation; grade IV, permanent edema distorting a limb, complicated as associated with irreversible skin changes, ie, fibrosis and papillae, as a result of inflammation of the skin; grade V, elephantiasis, massive edema distorting a leg with skin thickening, and changes in muscles - dystrophy, disabling the function of a limb. Group A underwent a monthly antiedematous therapy including a manual lymphatic drainage, multilayer bandaging, and IPC with the output pressure of I $20 \mathrm{mmHg}$. Group B underwent the same basic treatment as group A and IPC with the output pressure of $60 \mathrm{mmHg}$. Group C (control) underwent only a basic treatment - without IPC.

Abbreviations: R, right limb; L, left limb; IPC, intermittent pneumatic compression.

\section{Statistical analysis}

For the analysis of the parameters studied in the paper, the STATISTICA software version 10.0 (StatSoft Poland, Dell Inc., USA) was used. The uniformity of distribution of the patients' characteristics in groups A, B, and C was tested with the chi-squared test version of the highest reliability $\left(\chi^{2}\right)$ and with the Kruskal-Wallis homogeneity test. Statistically significant differences were considered when $P<0.05$. The nonparametric matched-pair Wilcoxon test was used to check whether a given parameter changed statistically significantly after the treatment compared to initial value $(P<0.05)$ within group (dependent variables). In contrast, the nonparametric test for independent variables - Kruskal-Wallis analysis of variance (ANOVA) examined the relationship between percentage changes in groups A, B, and C. However, the post hoc Tukey's test for multiple comparisons was used to find exact dependence resulting from analysis of variables between groups, differences in the changes between the groups in the limb volume, and edema values. Differences were statistically significant when $P<0.05$.

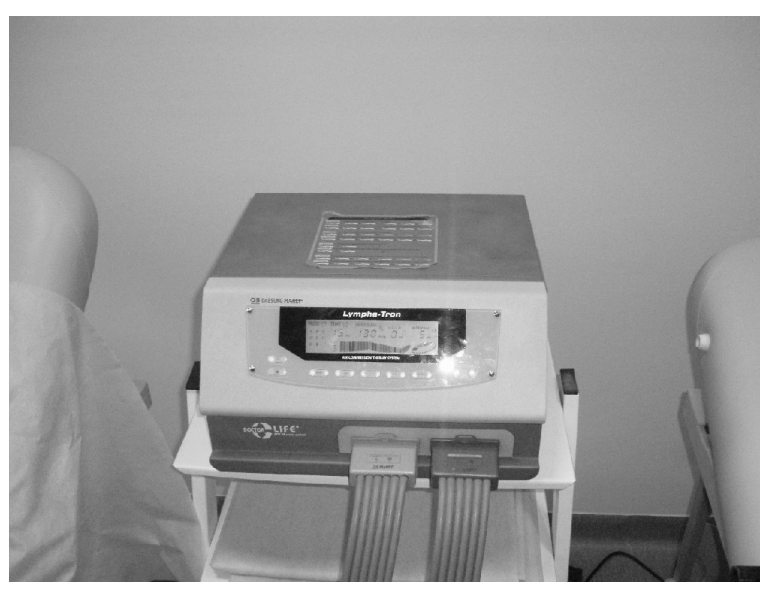

Figure 4 The IPC device.

Abbreviation: IPC, intermittent pneumatic compression.

\section{Results}

The analysis of dependent variables with the use of Wilcoxon matched pair test found a statistically significant decrease in the volume of right lower limb as compared to the initial parameters in all comparison groups (Table 5).

The Kruskal-Wallis ANOVA indicates a statistically significant difference between the groups $P(\mathrm{~A}, \mathrm{~B}$, C) $=0.00000$. Post hoc test indicated a significant advantage of group A in terms of a percentage reduction in the volume of the affected lower limb in relation to other comparison groups. By contrast, there was no difference observed between groups $\mathrm{B}$ and $\mathrm{C}$ : $P(\mathrm{~A}$ vs $\mathrm{B})=0.000002, P(\mathrm{~A}$ vs C) $=0.000000$, and $P(\mathrm{~B}$ vs $\mathrm{C})=0.7052$. The detailed results of the percentage changes in the volume of right lower limb are shown in Figure 7.

Likewise, a statistically significant reduction in the volume of the left lower limb in relation to the initial parameters was observed in each group (Table 6). It was also reported that there was a statistically significant difference between the groups $P(\mathrm{~A}, \mathrm{~B}, \mathrm{C})=0.0000$. Post hoc test indicated a significant advantage of group $\mathrm{A}$ in terms of a percentage

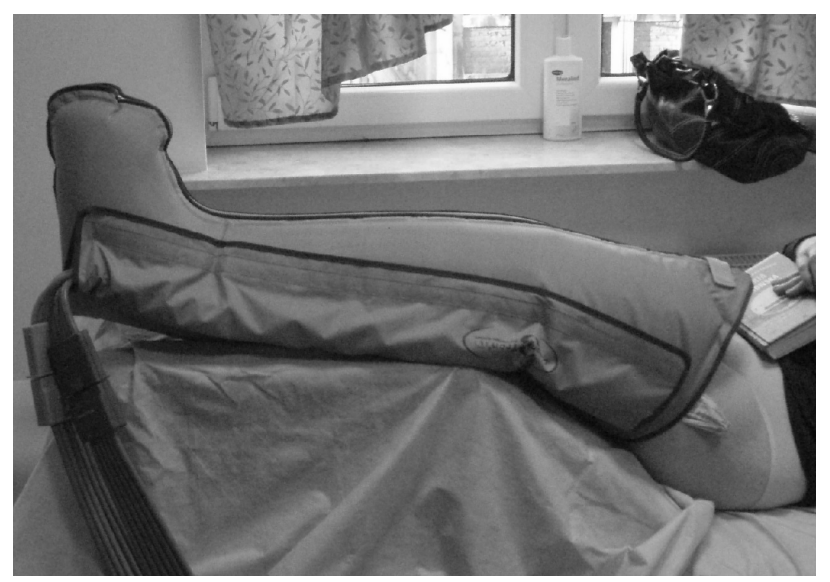

Figure 5 The 12-chamber IPC application.

Abbreviation: IPC, intermittent pneumatic compression. 


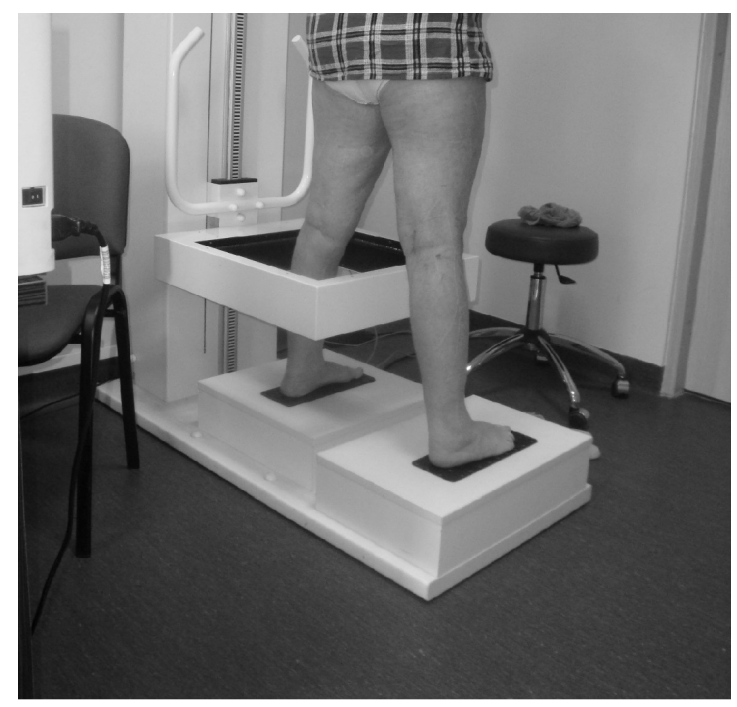

Figure 6 The Perometer 400T measurement.

reduction in the volume of the affected left lower limb in relation to other comparison groups. By contrast, there was no difference observed between groups $\mathrm{B}$ and $\mathrm{C}: P(\mathrm{~A}$ vs B $)=0.000000, P($ A vs $\mathrm{C})=0.000002$, and $P(\mathrm{~B}$ vs $\mathrm{C})=0.7093$. The detailed results of the percentage changes in the volume of left lower limb are shown in Figure 8.

\section{Discussion}

The worldwide consensus on the IPC parameters (high or low pressure in chambers) is not established. Olszewsk $\mathrm{i}^{18}$ believes that the external pressure exerted on the surface of a limb in order to effectively reduce accumulated lymph should be several times greater than the pressure inside the vessel acting directly on the outflow. He found, with the use of implanted cannula, that if the mean physiological pressure in the

Table 5 Between-group comparisons of changes in right lower limb volume $\left(\mathrm{cm}^{3}\right)$

\begin{tabular}{llll}
\hline & $\begin{array}{l}\text { Before } \\
\text { treatment }\end{array}$ & $\begin{array}{l}\text { After } \\
\text { treatment }\end{array}$ & P-value \\
\hline $\begin{array}{l}\text { Group A } \\
\text { Average }\end{array}$ & $14,423.34$ & $8,755.23$ & 0.00001 \\
$\quad$ SD & $4,781.12$ & $7,878.77$ & \\
Group B & & & \\
$\quad \begin{array}{l}\text { Average } \\
\text { SD }\end{array}$ & $14,562.02$ & $12,511.47$ & 0.00022 \\
Group C & $4,454.24$ & $8,954.43$ & \\
$\quad \begin{array}{l}\text { Average } \\
\text { SD }\end{array}$ & $14,078.22$ & $12,305.67$ & 0.00031 \\
\hline
\end{tabular}

Notes: Group A underwent a monthly antiedematous therapy including a manual lymphatic drainage, multilayer bandaging, and IPC with the output pressure of $120 \mathrm{mmHg}$. Group B underwent the same basic treatment as group A and IPC with the output pressure of $60 \mathrm{mmHg}$. Group $\mathrm{C}$ (control) underwent only a basic treatment - without IPC.

Abbreviation: SD, standard deviation; IPC, intermittent pneumatic compression.

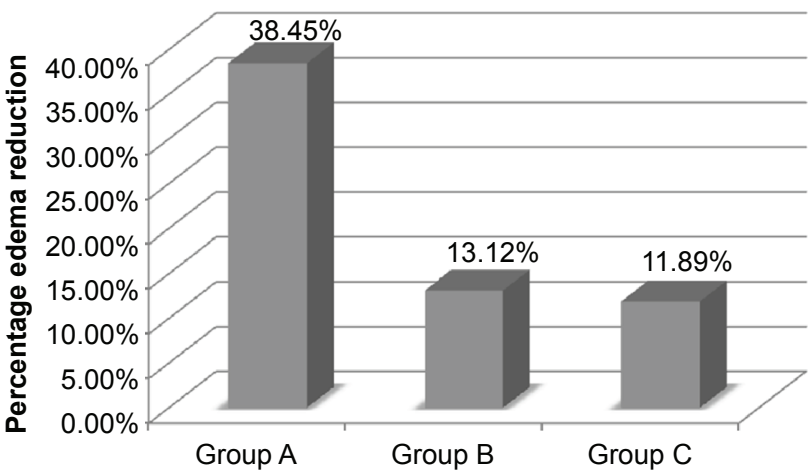

Figure 7 Comparison of percentage edema reduction in the right lower limb between groups $\mathrm{A}, \mathrm{B}$, and $\mathrm{C}$.

Notes: Group A underwent a monthly antiedematous therapy including a manual lymphatic drainage, multilayer bandaging, and IPC with the output pressure of $120 \mathrm{mmHg}$. Group B underwent the same basic treatment as group A and IPC with the output pressure of $60 \mathrm{mmHg}$. Group $\mathrm{C}$ (control) underwent only a basic treatment - without IPC.

Abbreviation: IPC, intermittent pneumatic compression.

superficial lymphatic vessel in the lower limb is $10-12 \mathrm{mmHg}$, then the external pressure (on skin) is $30-40 \mathrm{mmHg}$. Therefore, only greater external pressure can stimulate lymph drainage. For example, assuming a mechanical external compression equals $60 \mathrm{mmHg}$, the pressure acting inside the lymph vessel will amount to only approximately $15-20 \mathrm{mmHg}$ (and in accordance with the basic laws of physics by Laplace and Poiseuille, the flow can be initiated only at this value). In contrast, when the applied pressure is $100 \mathrm{mmHg}$, then the intravascular pressure may increase to $30-40 \mathrm{mmHg}$. Olszewski calculated that under any additional pressure of $2 \mathrm{mmHg}$, the lymph flow increases by a further $50 \mathrm{~mL}$ and recommends the use of the external pressure from $80 \mathrm{mmHg}$ to even $150 \mathrm{mmHg}$, and the treatment time should be 45-60 minutes.

On the other hand, Ponikowska et $\mathrm{a}^{15}$ argue that the level of pneumatic compression pressure should not exceed

Table 6 Between-group comparisons of changes in left lower limb volume $\left(\mathrm{cm}^{3}\right)$

\begin{tabular}{llll}
\hline & $\begin{array}{l}\text { Before } \\
\text { treatment }\end{array}$ & $\begin{array}{l}\text { After } \\
\text { treatment }\end{array}$ & P-value \\
\hline $\begin{array}{l}\text { Group A } \\
\text { Average }\end{array}$ & $13,902.11$ & $8,734.23$ & 0.00001 \\
SD & $4,423.33$ & $6,956.44$ & \\
Group B & & & \\
$\quad \begin{array}{l}\text { Average } \\
\text { SD }\end{array}$ & $14,103.23$ & $12,567.78$ & 0.00028 \\
Group C & $4,223.25$ & $9,123.84$ & \\
$\quad$ Average & $13,944.21$ & $12,270.67$ & 0.00023 \\
SD & $3,993.84$ & $9,563.86$ & \\
\hline
\end{tabular}

Notes: Group A underwent a monthly antiedematous therapy including a manual lymphatic drainage, multilayer bandaging, and IPC with the output pressure of $120 \mathrm{mmHg}$. Group B underwent the same basic treatment as group A and IPC with the output pressure of $60 \mathrm{mmHg}$. Group $\mathrm{C}$ (control) underwent only a basic treatment - without IPC.

Abbreviation: SD, standard deviation; IPC, intermittent pneumatic compression. 


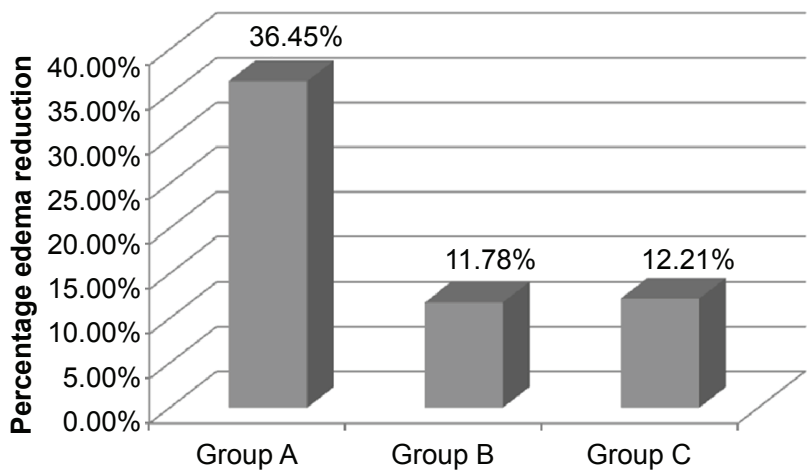

Figure $\mathbf{8}$ Comparison of percentage edema reduction in the left lower limb between groups $\mathrm{A}, \mathrm{B}$, and $\mathrm{C}$.

$40-50 \mathrm{mmHg}$, as higher parameters can lead to damage of the lymphatic vessels and have adverse consequences for the damaged venous valves such as lymphedema in patients with venous insufficiency, and the treatment may be not tolerated because of excessive pressure on the pain receptors in the skin.

Similar guidelines are also recommended by Woźniewski and Kołodziej, ${ }^{17}$ explaining that the pressure in the pneumatic compression $>60 \mathrm{mmHg}$ should not be applied in patients with lymphedema of the limbs (also of venous component) because higher pressure can be painful and may damage the skin vessels (lymphatic precollectors in the skin).

This paper is the first attempt, in the available literature, to compare two different (relatively low and high), but frequently used in everyday therapeutic practice (and sometimes even despite conflicting physical basis and the lack of reliable scientific foundations and reliable clinical trials) pressures in the IPC treatment within one experiment and based on a uniform study material, including patients with specially selected edema with mixed component, that is, phlebolymphedema. The innovation was also the use of accurate and noninvasive measurement of lower limb edema with the use of an innovative perometric test. So far, researchers have used only the methods with high measurement error, namely, a metric technique using a metric tape, to calculate the circumference of the limb volume from the formula for a truncated cone or by means of water displacement (hydrostatic method). The optoelectronic device Perometer $400 \mathrm{~T}$, used in our study, was the first trial in scientific research in the field of phlebolymphedema of the lower limbs.

Therefore, the obtained results can only be referred to individual reports in the literature on pneumatic compression therapy used in the treatment of edema in patients with chronic venous insufficiency of the lower limbs or slightly more numerous publications in the field represented by the therapy of the so-called secondary lymphedema, where the most research material include patients after gynecological and oncological surgeries with resection of the inguinal and/ or retroperitoneal lymph nodes.

The results obtained by Zaleska et al ${ }^{29,30}$ really correspond to our experience and seem to justify the application of high pressure inside the chambers during IPC, both in cases of mixed phlebolymphedema and postoperative lymphatic edema resulting from inguinal node resection after hysterectomy. The study used a multichamber compression sleeve, supporting the opinion that its effectiveness during treatment is higher than a single-chamber sleeve. A singlechamber filling time was different - relatively short and lasted 3 seconds and not 50 seconds (in the future, it is worth considering to conduct a comparative analysis of the clinical effectiveness of 50-second duration of compression in the case of phlebolymphedema). Besides, still three patients experienced discomfort and pain sensations during intermittent compression with a pressure of $120 \mathrm{mmHg}$, which led to termination of the treatment. In group B, where applied pressure value was $60 \mathrm{mmHg}$, there were two such cases. Our studies do not fully support the thesis that this therapy (especially high pressure) is always well tolerated by patients.

Abu-Own et $\mathrm{al}^{31}$ also advocated the use of multichamber compression. The study was performed in 17 healthy volunteers, where two types of devices for IPC were applied (multichamber compression exerting the compression of 40-55 mmHg and a single-chamber device exerting pressure all over the shank at the same time under a pressure of $60 \mathrm{mmHg}$ ) for a period of 10 minutes. The result was a significantly greater reduction in volume after each pressure when using the multichamber compression.

Similar conclusions on the application of higher pressure parameters in the treatment of lymphedema were drawn by Modaghegh and Soltan, ${ }^{32}$ stating that IPC is an extremely effective physical treatment (16-hour treatment and pressure value of $80-120 \mathrm{mmHg}$ ). It was found that the average reduction of edema in the affected limb was as high as approximately $75 \%$.

The available literature also presents critical works on the use of high pressure during IPC in cases of primary and secondary lymphatic edema of lower limbs. ${ }^{33-35}$ However, it must be critically assessed that most of these works lack comparison groups and blindness, and the studies were based on a small number of patients. 
The literature does not devote much place for studies in basic science. Certainly, a deeper understanding of all the mechanisms that occur under the influence of IPC within the lymphatic vessels and lower limb venous system would facilitate clinical activity. An interesting aspect of the testing is the analysis of thermographic images taken with infrared camera in patients with venous edema and trophic disorders of the skin (open sores). The research shows that the applied compression with pressure $>60 \mathrm{mmHg}$ increases the temperature of the lower leg and the temperature around the medial malleolus of treated patients (which is justified by stimulation of microcirculation). The lower pressure values did not cause this effect. ${ }^{23}$

In our work, we did not evaluate the financial costs of IPC; however, one has to agree with the fact that this method - apart from a one-off expense for the purchase of equipment - allows to perform physiotherapy treatments at home and does not require complicated service. Besides, it is available and relatively cheap (as for medical devices).

\section{Limitations of study}

There are limitations to this study, for example, the small number of subjects and lack of the follow-up results. Another potential limitation of our study is the lack of a pain relief and quality of life observation - larger aspects than only edema therapy. We acknowledge the need to continue this research in larger numbers of subjects, thus, according to statistical estimation, we would like to clarify that the population over 35-40 in each group is needed for further analysis of normal distribution and to use the parametric tests. At this moment, it was estimated that a power of test is 0.86 compared to parametric statistics conducted on large population with Gauss decay (30 subjects in one group). At the same time, we emphasize the pilot character of this study, which describes the insufficient utility of IPC with low pressure for lower leg phlebolymphedema. Our results should be confirmed on bigger population (perhaps with sham IPC - no pressure in chambers) especially because of lack of the sample size estimation.

\section{Conclusion}

The output pressure in chambers during IPC treatments is a factor that significantly affects the effectiveness of edema treatment, in patients with chronic venous insufficiency. IPC with a pressure inside the chambers of $120 \mathrm{mmHg}$ significantly helps to reduce phlebolymphedema. In contrast, it appears that treatments at a pressure of $60 \mathrm{mmHg}$ are ineffective and their use only in antiedematous therapy becomes pointless (in the scope of the study).

\section{Acknowledgment}

This work was supported in whole by a research project grant from the Polish Society of Lymphology (number PTL/01/2015).

\section{Disclosure}

The authors report no conflicts of interest in this work.

\section{References}

1. Adhikari A, Criqui M, Wooll V, et al. The epidemiology of chronic venous diseases. Phlebology. 2000;15(1):221-232.

2. Coleridge-Smith PD. The microcirculation in venous hypertension. Vasc Med. 1997;2(3):203-213.

3. Cossio JA. The epidemiology of varicose disease. Phlebolymphology. 1993;1:3-7.

4. Szyber P, Szyber P. Lower limb lymphoedema - therapeutic problem. Therapy. 2008;2(1):70-72.

5. Jawień A, Grzela T, Ochwat A. Prevalence of chronic venous insufficiency (CVI) in men and women of Poland. Multicenter cross - sectional study of 40,095 patients. Phlebology. 2003;18(3):110-122.

6. Fowkes FG, Evans CJ, Lee AJ. Prevelence and risk factors of chronic venous insufficiency. Angiology. 2001;52(1):5-15.

7. Kurz X, Kahn SR, Abenhaim L, et al. Chronic venous disorders of the leg: epidemiology, outcomes, diagnosis and management. Summary of an evidence-based report of the VEINES task force. Venous Insufficiency Epidemiologic and Economic Studies. Int Angiol. 1999;18(2):83-102.

8. Taradaj J, Urbanek T, Kloth LC, Romanelli M. Physical therapy in wound healing, edema, and urinary incontinence. Biomed Res Int. 2014; 2014:825826.

9. Olszewski WL, Cwikla J, Zaleska M, Domaszewska-Szostek A, Gradalski T, Szopinska S. Pathways of lymph and tissue fluid flow during intermittent pneumatic massage of lower limbs with obstructive lymphedema. Lymphology. 2011;44(2):54-64.

10. Albertazzi P, Steel SA, Bottazzi M. Effect of intermittent compression therapy on bone mineral density in women with low bone mass. Bone. 2005;37(5):662-668.

11. Bickel A, Shturman A, Sergeiev M, Ivry S, Eitan A, Atar S. The hemodynamic effect and safety of intermittent sequential pneumatic compression leg sleeves in patients with congestive heart failure. J Card Fail. 2014;20(10):739-746.

12. Dolibog P, Franek A, Taradaj J, et al. A comparative clinical study on five types of compression therapy in patients with venous leg ulcers. Int J Med Sci. 2014;11(1):34-43.

13. Smith PC, Sarin S, Hasty J, Scurr JH. Sequential gradient pneumatic compression enhances venous ulcer healing - a randomized trial. Surgery. 1990;108(5):871-875.

14. Taradaj J, Halski T, Ozon M, et al. Comparison of efficacy of the intermittent pneumatic compression with various pressures in reducing the primary lower extremity venous lymphedema of menopausal patients. Menopause Rev. 2013;17(6):472-477.

15. Ponikowska I, Górczyńska K, Szczepanowski A. Interval pneumatic pressotherapy in the treatment of veno-lymphatic system disorders of the lower limbs. Balneol Pol. 1997;39(1-2):87-93.

16. Woźniewski M, Dąbrowska G. Rehabilitation of people with peripheral vascular disease of the lower limbs. Reh Prakt. 2007;2(1):27-28.

17. Woźniewski M, Kołodziej J. Rehabilitation in Surgery. 1st ed. Warsaw: PZWL Publishing House; 2006.

18. Olszewski WL. The "third" circulation in human limbs-tissue fluid, lymph and lymphatics. Phlebologie. 2012;41(6):297-303.

19. Taradaj J, Kucharzewski M, Halski T, et al. Effect of pressure and duration of a single intermittent pneumatic compression to reduce the primary lymphedema in patient lower extremities with venous insufficiency. Wound Manage. 2013;10(1):7-11. 
20. Taradaj J, Halski T, Pilok K, et al. Assessment of the influence of a complex decongestive therapy on equability reduction of upper extremity lymphedema in patients after mastectomy. Wound Manage. 2009;6(1):15-18.

21. Gloviczki P, Comerota AJ, Dalsing MC, et al; Society for Vascular Surgery; American Venous Forum. The care of patients with varicose veins and associated chronic venous diseases: clinical practice guidelines of the Society for Vascular Surgery and the American Venous Forum. J Vasc Surg. 2011;53(5):2-48.

22. Lee BB, Baumgartner I, Berlien P, et al. Diagnosis and treatment of venous malformations consensus document of the International Union of Phlebology (IUP): updated 2013. Int Angiol. 2015;34(2):97-149.

23. Dolibog P, Franek A, Taradaj J, et al. A randomized, controlled clinical pilot study comparing three types of compression therapy to treat venous leg ulcers in patients with superficial and/or segmental deep venous reflux. Ostomy Wound Manage. 2013;59(8):22-30.

24. Eklöf B, Rutherford RB, Bergan JJ, et al; American Venous Forum International Ad Hoc Committee for Revision of the CEAP Classification. Revision of the CEAP classification for chronic venous disorders: consensus statement. J Vasc Surg. 2004;40(6):1248-1252.

25. Kim H, Lee ES. Major difficulties and information needs recognised by nurses in applying graduated compression stocking and intermittent pneumatic compression for deep vein thrombosis prophylaxis. J Clin Nurs. 2015;24(1-2):308-311.

26. Partsch H, Flour M, Smith PC. Indications for compression therapy in venous and lymphatic disease consensus based on experimental data and scientific evidence. Under the auspices of the IUP. Int Angiol. 2008; 27(3):193-219.

27. Williams K, Moore H, Davies A. Haemodynamic changes with the use of neuromuscular electrical stimulation compared to intermittent pneumatic compression. Phlebology. 2015;30(5):365-372.
28. Taradaj J, Halski T, Rosinczuk J, Dymarek R, Laurowski A, Smykla A. The influence of kinesiology taping on the volume of lymphoedema and manual dexterity of the upper limb in women after breast cancer treatment. Eur J Cancer Care (Engl). 2015 May 12. doi: 10.1111/ ecc.12331. [Epub ahead of print].

29. Zaleska M, Olszewski WL, Durlik M. The effectiveness of intermittent pneumatic compression in long-term therapy of lymphedema of lower limbs. Lymphat Res Biol. 2014;12(2):103-109.

30. Zaleska M, Olszewski WL, Jain P, et al. Pressures and timing of intermittent pneumatic compression devices for efficient tissue fluid and lymph flow in limbs with lymphedema. Lymphat Res Biol. 2013; 11(4):227-232.

31. Abu-Own A, Scurr JH, Coleridge Smith PD. Assessment of intermittent pneumatic compression by strain gauge plethysmography. Phlebology. 1993;8(2):68-71.

32. Modaghegh MHS, Soltan E. Newly designed SIPC device for management of lymphoedema. Indian J Surg. 2010;72(1):36-40.

33. Greene R, Fowler R. Physical therapy management of primary lymphedema in the lower extremities: a case report. Physiother Theory Pract. 2010;26(1):62-68.

34. Muluk SC, Hirsch AT, Taffe EC. Pneumatic compression device treatment of lower extremity lymphedema elicits improved limb volume and patientreported outcomes. Eur J Vasc Endovasc Surg. 2013;46(4):480-487.

35. Stanisic MG, Gabriel M, Pawlaczyk K. Intensive decongestive treatment restores ability to work in patients with advanced forms of primary and secondary lower extremity lymphoedema. Phlebology. 2012; 27(7):347-351.
Therapeutics and Clinical Risk Management

\section{Publish your work in this journal}

Therapeutics and Clinical Risk Management is an international, peerreviewed journal of clinical therapeutics and risk management, focusing on concise rapid reporting of clinical studies in all therapeutic areas outcomes, safety, and programs for the effective, safe, and sustained use of medicines. This journal is indexed on PubMed Central, CAS,

\section{Dovepress}

EMBase, Scopus and the Elsevier Bibliographic databases. The manuscript management system is completely online and includes a very quick and fair peer-review system, which is all easy to use. Visit http://www.dovepress.com/testimonials.php to read real quotes from published authors. 